\title{
INHIBITORS OF THE TRANSCRIBING ENZYMES
}

\author{
P. SENSI \\ Research Laboratories, Gruppo Lepetit S.p.a., Milan, Italy
}

\begin{abstract}
The enzymes which transcribe DNA synthesizing RNA (DNA-dependent RNA polymerases) have structural differences in eukaryotic and prokaryotic cells, as indicated by the fact, among others, that there are substances which inhibit their function selectively in prokaryotic cells (streptolydigin and the ansa antibiotics, such as rifamycins and streptovaricin) and in eukaryotic cells ( $\alpha$-amanitin). Ansa antibiotics inhibit the initiation of RNA synthesis, whereas streptolydigin interferes with RNA elongation. Among ansa antibiotics, rifamycins have been studied more extensively, in order to obtain semisynthetic derivatives which, besides a comparable in vitro activity, showed better pharmacokinetic properties in vivo. Rifampicin, 3-(4-methylpiperazinoiminomethyl) rifamycin SV, has been selected for the oral treatment of various bacterial infections. Furthermore, a series of correlations between structure and activity have been derived, leading to the recognition of the essential structural requirements of the rifamycin molecule for penetrating into the bacterial cell and for inhibiting the enzyme.

Further chemical modifications have been performed, with the aim of overcoming the emergence of resistance in bacteria.

Members of the streptovaricin complex and some semisynthetic rifamycins have also been found to inhibit the RNA-dependent DNA polymerase (reverse transcriptase) of oncogenic RNA viruses. Their selectivity of action against the reverse transcriptase in respect to the polymerases of normal cells has yet to be established.
\end{abstract}

\section{INTRODUCTION}

Chemotherapeutic agents used in the treatment of infectious diseases possess, as a necessary but not sufficient requisite, a selective toxicity against pathogens. Therefore, they must act on specific targets which are present in the parasite but are either absent in the host or sufficiently different to be discriminable in the two organisms. In some cases, selective toxicity depends on the fact that the chemotherapeutic agent can reach the specific target in the microorganism but not in the host cell because of a selective permeability.

The search for chemotherapeutic agents has generally proceeded in an empirical way, namely, by means of a massive screening of products obtained by chemical synthesis or from natural sources, such as antibiotics, and through comparative tests of toxicity on the microorganism and host. So far this empirical approach has produced a series of useful chemotherapeutic agents that nowadays permit a successful control of most infectious diseases. Notwithstanding such successes, the necessity persists of carrying on the search for new chemotherapeutic agents with higher selectivity of action, 
lower side-effects and an unchanged efficacy on the microorganisms resistant to current chemotherapeutic agents.

Probably, however, the search for new chemotherapeutic agents has reached a critical point. In fact, the number of new efficacious drugs produced in the last few years is very small although a systematic and massive effort has been maintained in the search for new synthetic compounds or microbial metabolites with antibacterial properties. On the other hand, the knowledge of cell structure and of comparative biochemistry has increased considerably. It has become clear that, besides the underlying unity of biochemical processes which occur in all forms of life, there are some differences in the biochemical pathways of diverse species. A knowledge of the structural or biochemical differences between prokaryotes and eukaryotes permits the selection of specific targets for new chemotherapeutic agents. It must be acknowledged frankly that, till now, such targets have been identified a posteriori. The discovery of chemotherapeutic agents has always preceded the explanation of their mechanism of action and, therefore, the characterization of the specific target on which they are directed. However, the interval of time elapsing between the discovery of a chemotherapeutic agent and the understanding of its mechanism of action is very short nowadays, tending to become an unitary process.

Presumably, the knowledge of biochemical processes in the various species may constitute, in the future, the basis for a rational development of new chemotherapeutic agents. It is clear that such a development does not only mean the ambitious possibility of designing a priori molecules suitable for hitting a particular target, that is the dream, too often not fulfilled, of each medicinal chemist. But the knowledge of particular targets allows the setting up of definite biological laboratory tests, fit for selecting products with a given mechanism of action. At the same time, this knowledge allows an orientation of the chemical or biochemical synthesis towards classes of products which, at least theoretically, could interfere with the chosen target.

A number of enzymatic systems having the same role but different structures in various species, have been discovered so far. They can be chosen as specific targets useful in the search for new chemotherapeutic agents. As a classical example, I would cite the dihydrofolate reductase enzyme. This enzyme catalyzes the synthesis of tetrahydrofolic acid, a cofactor of the $C_{1}$-transferase enzyme, which participates in the synthesis of purines and certain amino acids both in prokaryotes and eukaryotes. Dihydrofolate reductase is inhibited by a number of 2,4-diaminopyrimidines. The synthesis and testing of a large number of 2,4-diaminopyrimidines and related substances, revealed that considerable selectivity could be achieved through molecular modification of the inhibitor. Some substances in this group have found clinical applications. Table 1 shows the selective action of pyrimethamine and trimethoprim against dihydrofolate reductase from different sources, and explains their use respectively as antimalarial and antibacterial agents ${ }^{1}$.

Another class of specific targets is constituted by the transcriptases, enzymes which synthesize RNA using DNA as a template (DNA-dependent RNA polymerases). These enzymes have a analogous role, but a different structure, in prokaryotes and eukaryotes. This is shown by the fact that there are substances that selectively block their function either in eukaryotes $(\alpha-$ 
INHIBITORS OF THE TRANSCRIBING ENZYMES

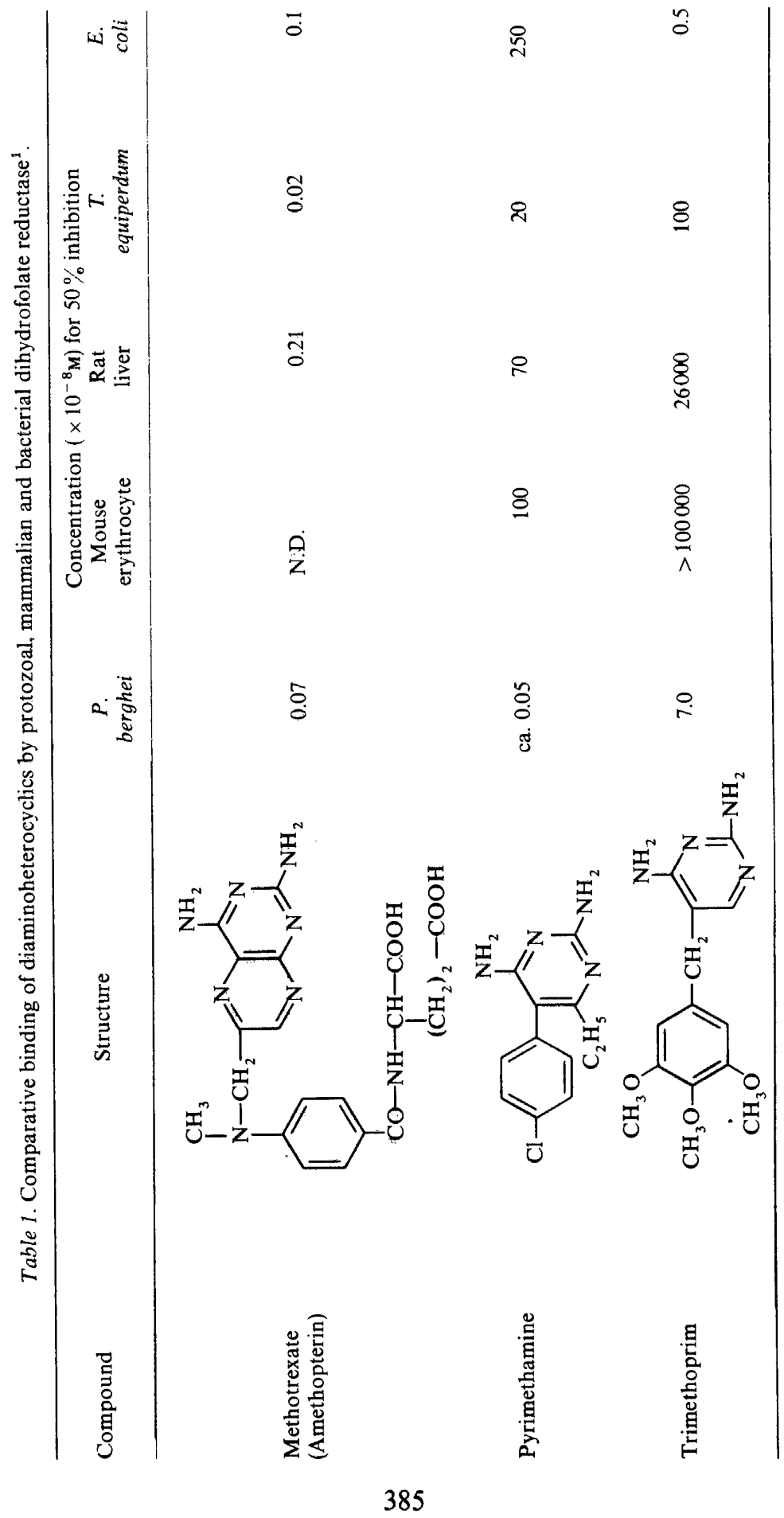




\begin{tabular}{lcc}
\hline & Bacteria & Nucleoplasma of eukaryotes \\
\cline { 2 - 3 }$\alpha$-Amanitin & - & + \\
Streptolydigin & + & - \\
Most rifamycins and streptovaricins & + & - \\
\hline
\end{tabular}

amanitin) or in prokaryotes (streptolydigin and ansamycin antibiotics, such as the rifamycins and streptovaricins). Table 2 shows the selective activity of these inhibitors. The discovery of such inhibitors has preceded the understanding of their mechanism of action, but the subsequent knowledge of this mechanism has catalyzed the search for analogous structures, obtainable, for instance, through chemical modifications of natural products, in order to obtain inhibitors of transcriptases in species others than sensitive bacteria. The results of this search, together with its prospects, are just the subjects of this report.

\section{TRANSCRIPTASE (DNA-DEPENDENT RNA POLYMERASE): STRUCTURE AND FUNCTION}

Transcriptase is the enzyme which catalyzes the polymerization of four ribonucleoside triphosphates into RNA, by transcribing a DNA template. In this way, the genetic information is transferred to RNA from DNA, with a sequence that is complementary to that of DNA template.

\section{Eukaryotic transcriptase}

The structure and the functioning of eukaryotic transcriptase is not well understood. At least three DNA-dependent RNA polymerases have been distinguished in eukaryotes. Polymerase I resides in the nucleolus and polymerase II and III in the nucleoplasm. They can be separated by chromatography on a DEAE-Sephadex column. Their reciprocal ratios seem to be different among the various species, and in the subsequent stages of development in the same species. Polymerase I synthesizes mainly, but not exclusively, ribosomal RNA; polymerase II synthesizes the bulk of nucleoplasmic RNA species, and polymerase III has no defined role as yet ${ }^{2}$. Recent studies on the structure of polymerase II from calf thymus and rat liver indicate that the molecule contains four components with molecular weight respectively of $190000,150000,35000$ and 25000 . Another species of polymerase II, with the largest component having a molecular weight of 170000 , has been identified in the same preparations. One of these forms may be derived from the other ${ }^{3}$.

\section{Prokaryotic transcriptase}

This enzyme has been studied in several organisms. Most information has been obtained with the RNA polymerase from Escherichia coli. However, there are good grounds for believing that the structure and properties of this enzyme are very similar in the various kinds of bacteria. 
Table 3. Composition of bacterial RNA polymerase

Molecular weight

Complete enzyme at low salt concentration

990000

Complete enzyme at high salt concentration

495000

containing: $2 \alpha$-particles

$1 \beta$-particle

40000 each

$1 \beta^{\prime}$-particle

155000

$1 \sigma$-factor

165000

95000

The RNA polymerase of $E$. coli is constituted of several subunits: two $\alpha$, $\beta, \beta^{\prime}$ and $\sigma$ (see Table 3$)^{4}$. All together, they constitute the holoenzyme, and the first four subunits constitute the core enzyme.

The enzymatic reaction occurs through the following steps:

(i) Binding. The enzyme (Enz) binds the template (DNA):

$$
\mathrm{DNA}+\mathrm{Enz} \rightleftharpoons \mathrm{DNA}-\mathrm{Enz}
$$

(ii) Initiation. At the initiation site, the DNA-Enz complex binds a purine nucleoside triphosphate which will constitute the 5 -terminal of the RNA chain, with the formation of a ternary complex :

$$
\text { DNA-Enz }+ \text { PPPPur } \rightleftharpoons \text { DNA-Enz-PPPPur }
$$

A second nucleoside triphosphate (PPPX, X = purine or pyrimidine nucleoside) is then bound with the formation of the first phosphodiester bond and elimination of pyrophosphate (PPy):

$$
\text { DNA-Enz-PPPPur + PPPX } \rightleftharpoons \text { DNA-Enz-PPPPur-PX + PPy }
$$

(iii) Polymerization. The enzyme migrates on DNA, while the nucleoside monophosphates PX, complementary to those of the DNA template, are added to the $3^{\prime}$ end of the growing RNA chain:

DNA-Enz-PPPPur-PX $+n_{1}$ PPPX $\rightleftharpoons$ DNA-Enz-PPPPur- $(\text { PX })_{n}+n_{1}$ PPy

(iv) Termination. When the transcribing machinery reaches the end of a cistron or of a polycistronic message, the polymerization process stops and the DNA-Enz-RNA complex dissociates:

$$
\text { DNA-Enz-PPPPur-(PX) })_{n} \rightleftharpoons \text { RNA + DNA + Enz }
$$

The processes of initiation and termination are more complex than indicated in the above simplified scheme, because they require other factors regulating them. The $\sigma$ unit has a role in the recognition and initiation of transcription of certain genes on DNA, but the process of chain elongation is determined by the core enzyme.

The structural and functional differences between RNA polymerase of prokaryotes and eukaryotes may constitute the basis for a rational development of chemotherapeutic drugs, acting on this specific target. 


\section{SPECIFIC INHIBITORS OF TRANSCRIPTASE}

\section{Specific inhibitors of eukaryotic transcriptase}

$\alpha$-Amanitin. $\alpha$-Amanitin is a highly toxic cyclic octapeptide, isolated from the poisonous fungus Amanita phalloides ${ }^{5}$ (Figure 1). It is a potent specific inhibitor of DNA-dependent RNA polymerase II of eukaryotes, while it does not inhibit nucleolar polymerase I and polymerase III of eukaryotes and

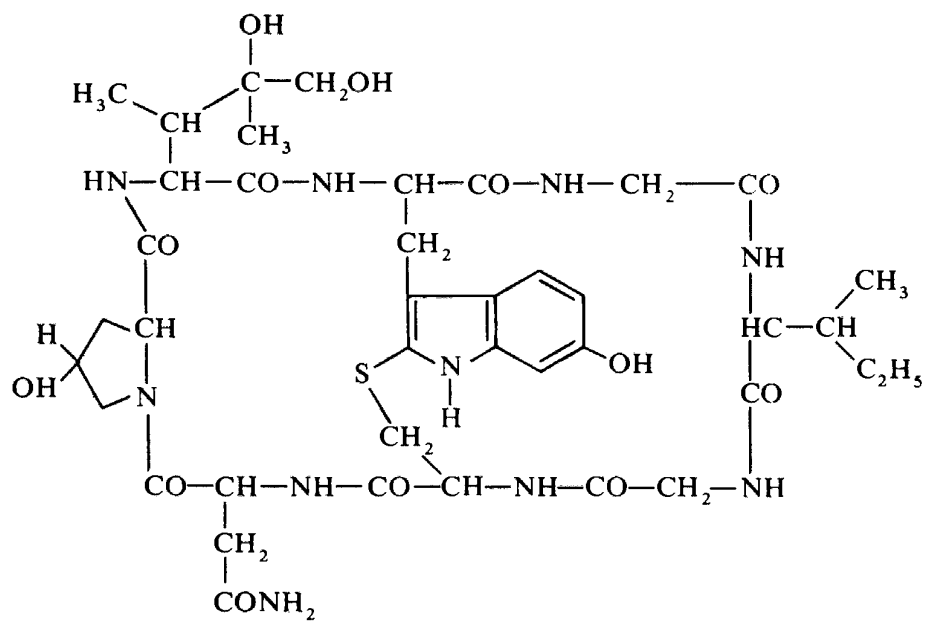

Figure 1. $\alpha$-Amanitin.

bacterial RNA polymerase. As an illustration of the degree of specificity, it can be cited that nucleolar RNA polymerase II from rat liver is inhibited to the extent of 50 per cent at $10^{-8} \mathrm{M}$ and to the extent of 100 per cent at $10^{-6} \mathrm{M}$ of $\alpha$-amanitin, while at the same concentrations, neither polymerase I and III of eukaryotes nor prokaryotic polymerase are inhibited to any significant extent ${ }^{6,7}$. The enzymatic reaction is blocked immediately after adding the inhibitor, which seems to act at the stage of RNA-chain elongation. The eukaryotic RNA polymerase from yeast is much less sensitive to the action of $\alpha$-amanitin than the mammalian enzyme ${ }^{8}$.

$\alpha$-Amanitin can constitute a remarkable example of the possibility of finding substances with a selectivity of action on enzymes that, although having a similar role, have a different structure in the various species. Furthermore, its polypeptidic nature could constitute a suitable model for the synthesis and testing of analogous polypeptidic compounds, in order to obtain information concerning the part of the molecule of $\alpha$-amanitin responsible for the binding to RNA polymerase II of eukaryotes. It is possible that, by introducing suitable groups such as aminoacidic residues, the molecule may acquire the property of binding to other polymerases. 


\section{Specific inhibitors of prokaryotic transcriptase}

Streptolydigin. Streptolydigin is an antibiotic produced by Streptomyces lydicus ${ }^{9}$. Its structure is shown in Figure 2. It exhibits in vitro activity primarily against streptococci, diplococci and clostridia and is relatively nontoxic. It acts by binding and thus specifically inhibiting bacterial RNA polymerase. In contrast, it has no effect on polymerase from calf thymus ${ }^{10}$. Its binding to

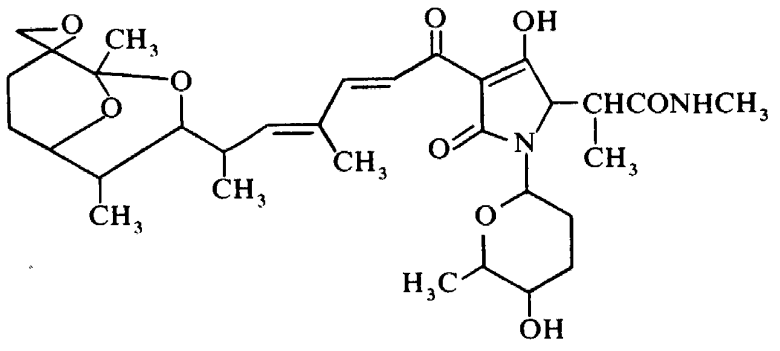

Figure 2. Streptolydigin.

the bacterial enzyme seems to be rather weak, since the inhibition is reversed by dilution. The concentration of antibiotic required for complete inhibition is fairly high (about $10^{-4} \mathrm{M}$ ), although a 50 per cent inhibition is obtained at about $7 \times 10^{-6} \mathrm{M}$. Streptolydigin interferes with the process of RNA chain elongation, primarily by affecting the rate of phosphodiester bond formation ${ }^{11}$. Only at high concentrations of the drug is the initiation process affected, because the formation of the first phosphodiester bond is also inhibited.

Chemical modifications of streptolydigin have not been performed, so it is not possible to elucidate which groups of the molecule are responsible for the binding to the enzyme.

Streptolydigin has no clinical application, although it shows the requisite of a selective activity on prokaryotes. It is opportune to recall again the fact that the selectivity of action is an essential, but not sufficient requisite for a chemotherapeutic agent.

Rifamycins, tolypomycins and streptovaricins. Rifamycins, together with tolypomycins and streptovaricins, are natural ansa compounds in which an aliphatic bridge spans an aromatic system.

Rifamycins have been isolated from the fermentation broth of Streptomyces mediterranei as a complex of at least five antibiotics indicated as $A, B, C, D, E^{12,13}$. The structure of rifamycin $B$ (and of the related compounds rifamycin O, S and SV) (Figure 3) has been elucidated by chemical ${ }^{14-16}$ and crystallographic ${ }^{17}$ methods.

Other rifamycins have been isolated from the fermentation broths of S.mediterranei or its mutants : rifamycin $\mathrm{Y}^{18,19}$, rifamycin $\mathrm{L}^{20}, 27-\mathrm{O}$-demethylrifamycin B, 27-O-demethylrifamycin SV and its deacetyl derivative ${ }^{21}$. Isolation of Streptomycetes or Nocardia strains producing rifamycin $\mathrm{O}$ has been reported by Japanese researchers ${ }^{22,23}$. A mutant able to produce directly rifamycin SV has been also obtained ${ }^{24}$. A list of all natural rifamycins is reported in Figure 5. Besides the natural rifamycins, several hundred deri- 


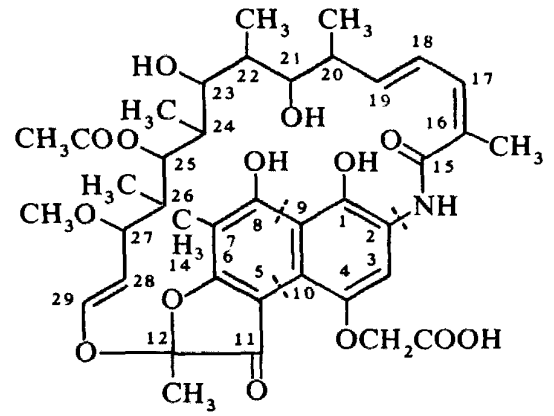

Rifamycin B (I)<smiles>Oc1cc(I)c(I)c(I)c1I</smiles>

Rifamycin SV (IV)<smiles>COC1(OC(C)=O)C=C(I)C(=O)C(I)=C1I</smiles>

Rifamycin O (II)<smiles>CC1=CC(=O)C(C)C(=O)C=C(I)C1=O</smiles>

Rifamycin S (III)

Figure 3. Structural relationship among rifamycin B, O, S and $\mathrm{SV}^{\dagger}$.

vatives have been obtained through chemical modifications of rifamycin $B$, with the aim of obtaining products for therapeutic applications in the field of bacterial infections. These extensive studies have not only yielded three semisynthetic rifamycins now in clinical use (namely, rifamycin SV, rifamide and rifampicin) (Figure 6), but have led to the recognition of the main structural requirements for penetration into bacterial cell and for inhibition of the enzyme.

† The numbering system followed in this text for the rifamycins is that originally used by Prelog $e t a l .^{14-16}$ to identify the individual carbon atoms and their substituents. This numbering

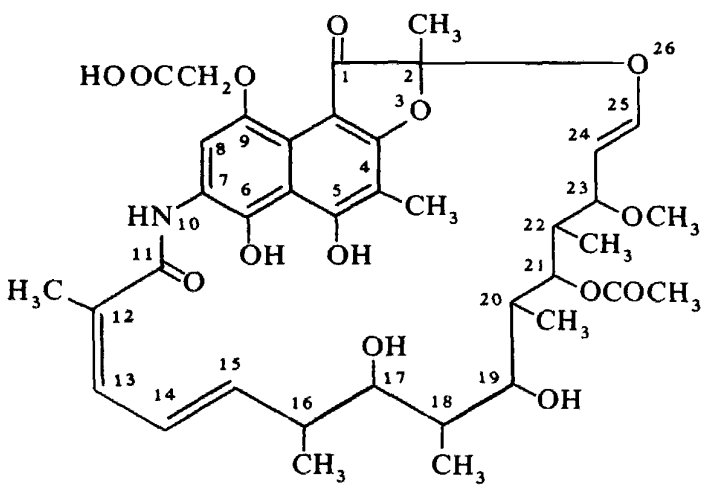

Figure 4. Numbering svstem for rifamvcin B according to IUPAC rules.

system has been used so far in all literature on the rifamycins and related 'ansamycins'. The orientation and numbering system for the rifamycins, according to the IUPAC rules, is shown in Figure 4. 


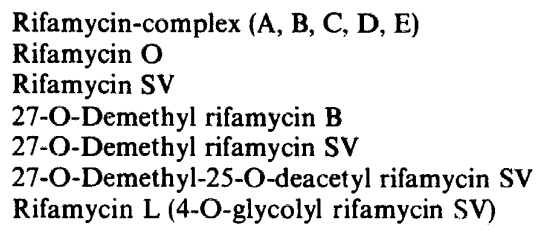

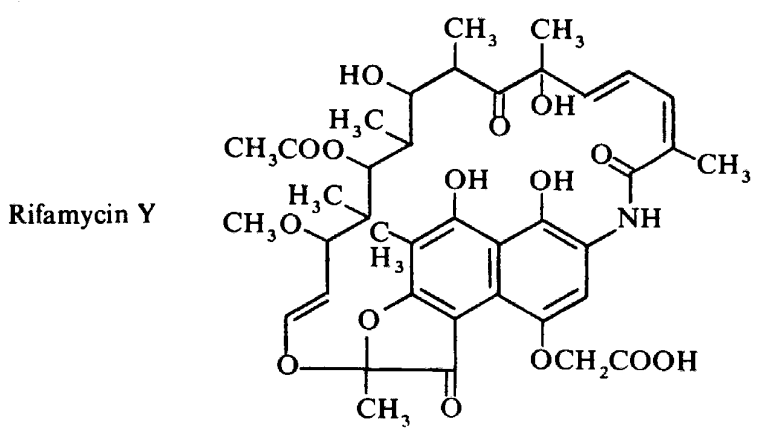

Figure 5. Natural rifamycins.

Tolypomycin (Figure 7) is an antibiotic substance produced by S. tolypophorus $^{25,26}$. From its structure it can be considered a member of the rifamycin family, the main difference being the presence of the aminosugar, tolyposamine, in position 4 . The product of mild acid hydrolysis, tolypomycinon, corresponds to rifamycin $S$ with a methyl group and the adjacent double bond replaced by the cyclopropane ring and the carbonyl group, respectively.

Streptovaricin, produced by $S$. mirabilis ${ }^{27}$, is a complex mixture of several related compounds whose structures are indicated in Figure $8^{28,29}$.

Rifamycins, tolypomycins and streptovaricins are very active against Gram-positive bacteria and mycobacteria. Some members of this large group of natural and semi-synthetic antibiotics show also moderate activity against Gram-negative bacteria. Microorganisms resistant to one class of these antibiotics are also resistant to the others.

The mechanism of action on bacteria is identical for rifamycins, streptovaricins and tolypomycins. It will be referred to in detail here for the rifamycins, and in particular for rifampicin, which have been studied more extensively.

Rifamycins selectively inhibit the synthesis of all cellular RNA in sensitive bacteria ${ }^{30}$, because they are potent inhibitors of the bacterial DNA-dependent RNA polymerase ${ }^{31,32}$. A concentration of $2 \times 10^{-8} \mathrm{M}$ of rifamycin causes a 

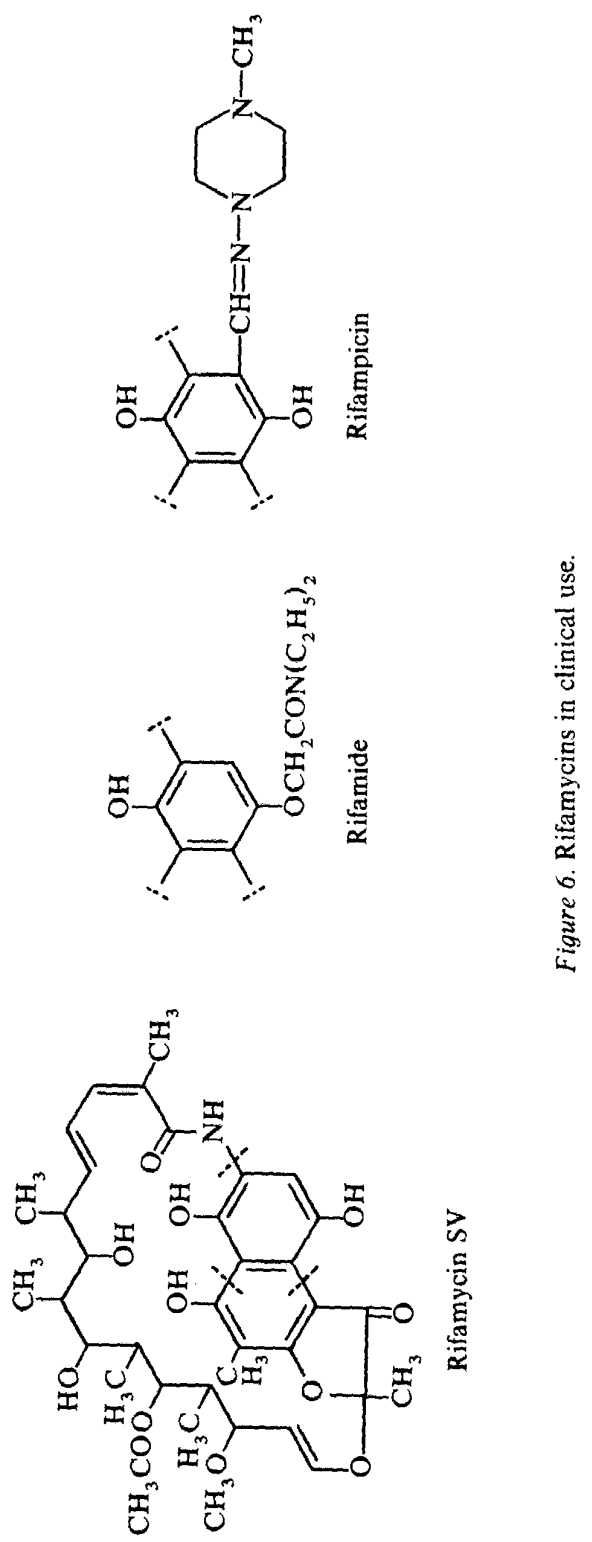
INHIBITORS OF THE TRANSCRIBING ENZYMES

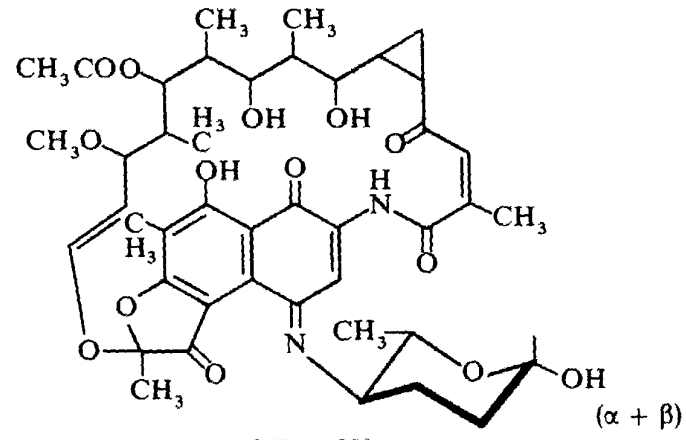<smiles>COC(C)C(C)C(OC(C)=O)C(C)C(C)C(O)C(C)C(O)C1CC1C(=O)/C=C(/C)C(=O)NC1=CC(=O)c2c(c(O)c(C)c3c2C(=O)C2(C)OC3=CC2C)C1=O</smiles>

Figure 7. Tolypomycin $\mathrm{Y}$ (above) and tolypomycinon (below).

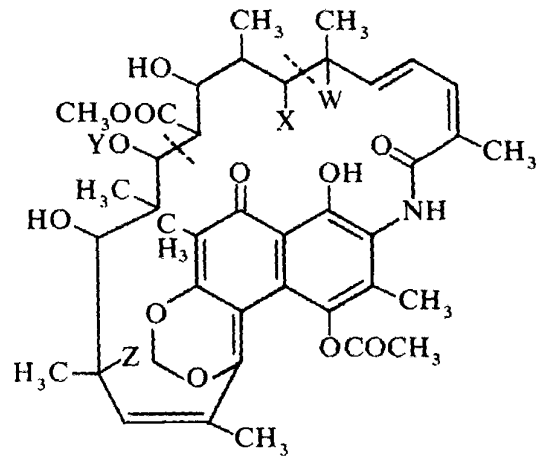<smiles>[Y]C(C)C(=O)C(C)C(=O)O</smiles>

Figure 8. Structural formulas of streptovaricins. 
50 per cent decrease of the bacterial enzymatic activity. In intact bacteria the inhibition by rifamycins of protein synthesis and of DNA synthesis is a consequence of the primary effect of these antibiotics on RNA synthesis ${ }^{33,34}$. The mammalian RNA polymerase is resistant to even very high concentrations of rifamycins ${ }^{31}$ (Figure 9).

The high ratio of activity of rifamycins against bacterial and mammalian RNA polymerase could not be utilized for chemotherapeutic applications if these antibiotics inhibited the RNA polymerase of mitochondria of eukaryotic organisms, which have some biochemical properties similar to those of prokaryotes. Results of studies on the activity of rifamycins on mitochondrial RNA polymerase are conflicting. Some reports indicate that rifampicin does not inhibit the RNA synthesis by mitochondria from yeast ${ }^{35,36}$, Neurospora $^{37}$ and hamster cells ${ }^{38}$, whereas those cases where rifampicin has been reported to affect mitochondrial-RNA synthesis, i.e. in rat liver or bovine heart ${ }^{39-41}$, very high concentrations of antibiotics were needed for the inhibition.

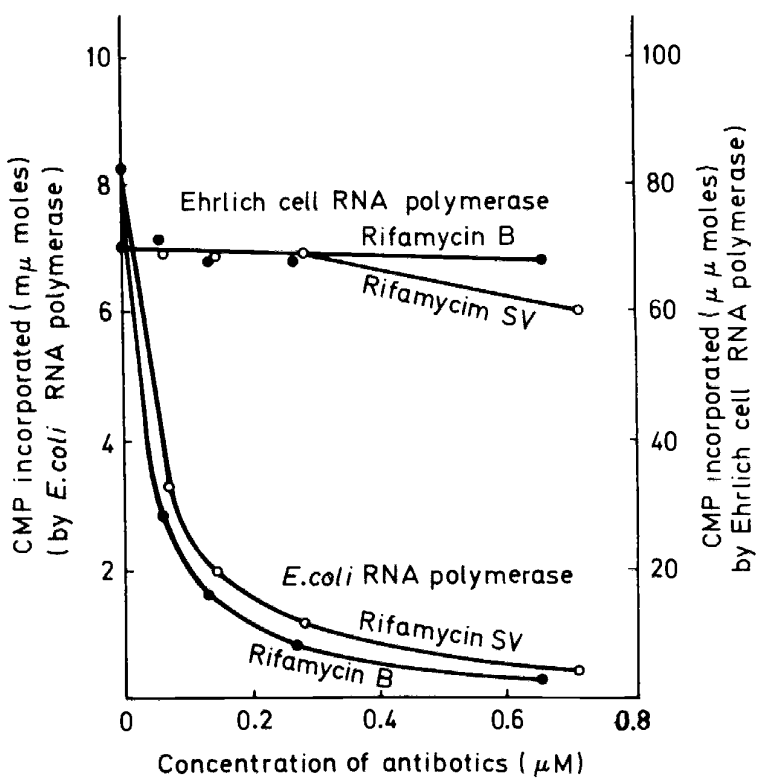

Figure 9. Effect of rifamycins on RNA polymerase reactions of E.coli and Ehrlich carcinoma cells $^{31}$.

In bacteria rifamycins inhibit the initiation of RNA synthesis and have no effect on chain elongation ${ }^{31,42}$. They do not inhibit the formation of the enzyme-DNA complex, so their activity is probably due to their ability to modify the conformation of the enzyme, inactivating it before the incorporation of the first purine nucleotide of the RNA chain. As previous incubation of the holoenzyme with the natural DNA template in presence of $\mathrm{Mg}^{2+}$ gives protection against the inhibitory effect of rifamycins, it seems likely that these antibiotics inhibit the transformation of the DNA-enzyme 
complex into an activated form, during which the enzyme binds to the specific promoter sites on the DNA ${ }^{43-45}$. Rifamycins inhibit the RNA polymerase forming a rather stable complex with $\mathrm{it}^{46-48}$. The binding between enzyme and rifamycins with the formation of an equimolecular complex is a very quick process ${ }^{46}$. The complex is rather stable but no covalent linkages are involved because it slowly exchanges with free rifamycin ${ }^{48}$, and is dissociated with $6 \mathrm{M}$ guanidine hydrochloride ${ }^{43}$. Rifamycins also bind to the enzyme during the RNA chain elongation, but have no effect on this process, perhaps because the enzyme, at this stage, is resistant to conformational changes induced by the antibiotic.

Bacterial mutants resistant to rifamycins possess an altered RNA polymerase which is not inhibited by rifamycins ${ }^{49,50}$. Studies on the interaction between rifamycins and the various subunits of the enzyme have shown that rifamycin binds to the $\beta$-subunit ${ }^{51}$. This has been confirmed by the finding that, in rifampicin-resistant mutants, RNA polymerase contains a subunit with an electrophoretic mobility different from that of wild-type $\beta$, likely as a consequence of the substitution of a single charged amino acid ${ }^{52,53}$.

\section{STRUCTURAL MODIFICATIONS OF THE RIFAMYCINS AND THEIR EFFECT ON ANTIBACTERIAL ACTIVITY}

\section{Changes affecting penetration of rifamycins into the bacterial cell}

With few exceptions, most rifamycins are active against bacteria when they are active against the bacterial RNA polymerase and vice-versa (Table 4). The exceptions, indicated as class 3 in the Table, are constituted by rifamycins bearing a strong polar group (e.g. a free carboxy group), which are active against the enzyme but have little or no activity against intact bacterial cells, because a permeability barrier exists, which the polar derivatives cannot pass $^{47,54}$. Such derivatives would be discarded, as inactive or little active, in a blind conventional screening for the search for antibacterial agents. On the contrary, a screening directed against the target enzyme, the bacterial RNA polymerase, would select such derivatives, leaving to the medicinal chemist the possibility of modifying their structure in order to increase their permeability through the cell wall. Also rifamycin B belongs to this group; but although inactive per se, it is easily transformed into rifamycin $\mathrm{S}$, which is very active, and only as a result of this unusual property has not been neglected ${ }^{55}$.

Table 4. Relationship between inhibition of bacterial growth and of bacterial RNA polymerase

\begin{tabular}{lcc}
\hline \multicolumn{1}{c}{ Class } & \multicolumn{2}{c}{ Activity of rifamycins } \\
\cline { 2 - 3 } & $\begin{array}{c}\text { on bacterial } \\
\text { cells }\end{array}$ & $\begin{array}{c}\text { on bacterial } \\
\text { RNA polymerase }\end{array}$ \\
\hline $\begin{array}{l}1 \text { Most active rifamycins } \\
2 \text { Most inactive rifamycins } \\
\text { Rifamycins unable to cross the bacterial cell }\end{array}$ & + & + \\
$\begin{array}{l}\text { wall } \\
\text { Rifamycins which undergo structural modi- } \\
\text { fication during antibacterial test }\end{array}$ & - & + \\
\hline
\end{tabular}


Although large variations exist in the sensitivity of different intact bacteria to a particular rifamycin, no such differences are apparent when the isolated transcriptase is examined. Thus in the case of the Gram-negative bacteria permeability plays an overriding role in determining the sensitivity to rifamycins; their enzyme has an intrinsic sensitivity very similar to that of the Gram-positive bacteria.

A few rifamycins show activity on the intact cells and no activity on the RNA polymerase and this is due to the fact that they undergo some chemical modification during the antibacterial test. For example 8 -acyl rifamycins are inactive against the enzyme ${ }^{54}$, but kill the bacteria because they undergo deacetylation during the incubation.

\section{Structure-activity relationship for inhibition of transcriptase from sensitive bacteria}

By making use of the large range of semi-synthetic rifamycins available, it has been possible to investigate the essential structural requirements of the rifamycin molecule for inhibition of the bacterial RNA polymerase. So far results have shown that changes of the ansa chain involving substitution or elimination of the two hydroxy groups at C-21 and C-23 yield inactive products, while the acetoxy group at C-25 and the methoxy group at C-27 seem to be unessential requirements. For example, methanolysis of rifamycin $\mathrm{S}$ in mildly acidic conditions, yields the 23,27-epoxy derivative which no longer has the hydroxy group at C-23 and is inactive ${ }^{47,59}$. Also the $21-$ and $23-\mathrm{O}-$ acetyl rifamycins $\mathrm{S}$ have a very poor activity ${ }^{58}$. On the other hand, the acetoxy group at C-25 can be hydrolyzed without loss of activity ${ }^{59}$. Among natural rifamycins, the 27-O-demethyl rifamycin S shows a high level of activity, while rifamycin $\mathrm{Y}$, with a keto group instead of an hydroxy group at $\mathrm{C}-21$, is practically inactive ${ }^{18}$. It is interesting to point out that tolypomycin $\mathrm{Y}$ and streptovaricin $\mathrm{A}, \mathrm{C}$ and $\mathrm{D}$, which are very active, all have the hydroxy groups in positions corresponding to the 21 and 23 of the rifamycins.

Functional modifications which, although leaving the hydroxy groups at C-21 and C-23 unaltered, produce important changes in the conformation of the ansa chain, also give inactive or only moderately active products. Thus hexahydro rifamycin $S$ shows very little antibacterial activity, while the dihydro and the tetrahydro analogues are quite active ${ }^{56,59}$. The monoand di-epoxides of rifamycin $\mathrm{S}$, obtained by treatment with monoperphthalic acid, show a poor activity and the iminomethylether, obtained by treatment with $\mathrm{CH}_{3} \mathrm{I}$, has a negligible activity ${ }^{56,59}$ (see Figure 10). In all these cases, the molecular models and certain physicochemical characteristics indicate that such chemical changes have caused a modification in the conformation of the ansa chain.

The hydroxy group attached at $\mathrm{C}-8$ of the chromophoric moiety also seems to be an essential structural requirement, since 8 -methoxy rifamycin $\mathrm{S}$ is inactive $^{60}$. On the contrary, the hydroxy groups on the positions $\mathrm{C}-1$ and $\mathrm{C}-4$ can be substituted by keto groups without loss of activity. The same quinonehydroquinone system does not appear essential, since 4-deoxyrifamycin is also quite active, although its activity is approximately one-tenth that of rifamycin $\mathrm{SV}^{56}$ (see Figure 12). 


\section{INHIBITORS OF THE TRANSCRIBING ENZYMES}

(1) By chemical modifications

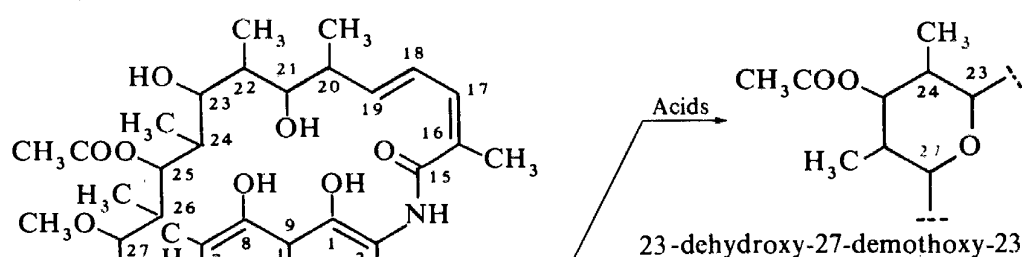

Antimicrokial activity

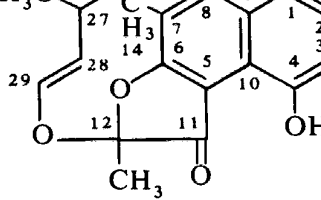

23 -dehydroxy-27-demothoxy-23,27-epoxy

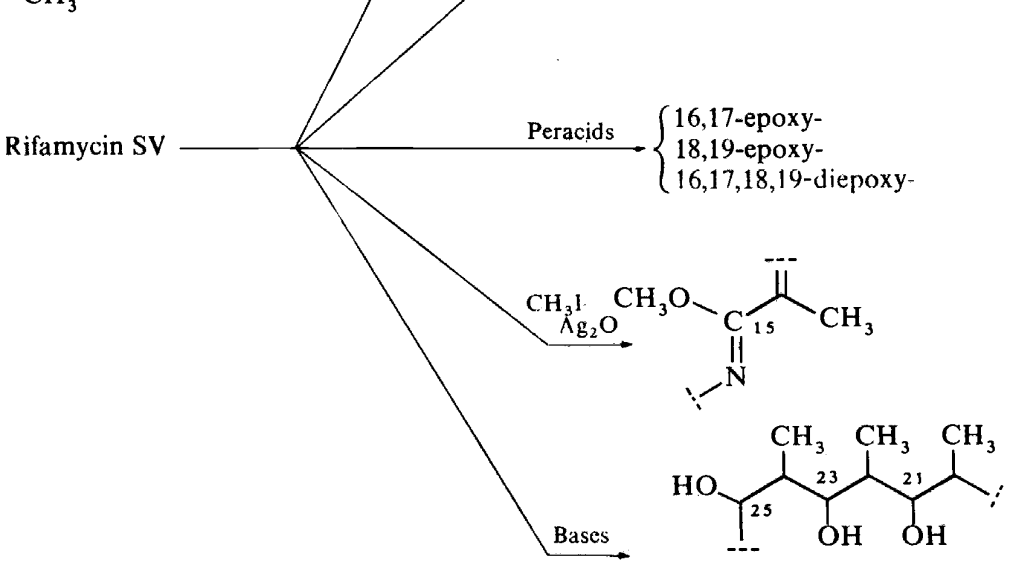

(2) By fermentation

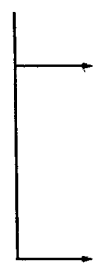<smiles>CC(C)OC(C(C)C(C)O)C(C)C(O)C(C)I</smiles><smiles>O[C@@H](I)/C=C\I</smiles>

27-O-demethyl

(3) By fermentation and chemical modification

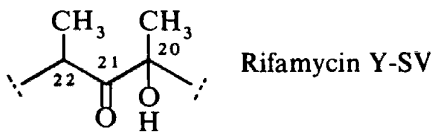

Figure 10. Modifications in the aliphatic ansa chain of rifamycin SV and related antimicrobial activity on $S$. aureus. $\left(+++\right.$ indicates m.i.c. of the order of $<0.02 \mu \mathrm{g} \mathrm{ml}^{-1} ;++0.02-0.2$; $+>0.2-2.0:->2.0 \mu \mathrm{g} \mathrm{ml}^{-1}$ ). 
Thus, from the data accumulated until now, it can be inferred that the essential structural requirements for the inhibition of the bacterial RNA polymerase, are free hydroxy groups at C-21, C-23 and C-8, together with a certain conformation of the ansa chain, leading to a definite geometric relationship between these groups, as can be seen in the three-dimensional model (Figure 11).

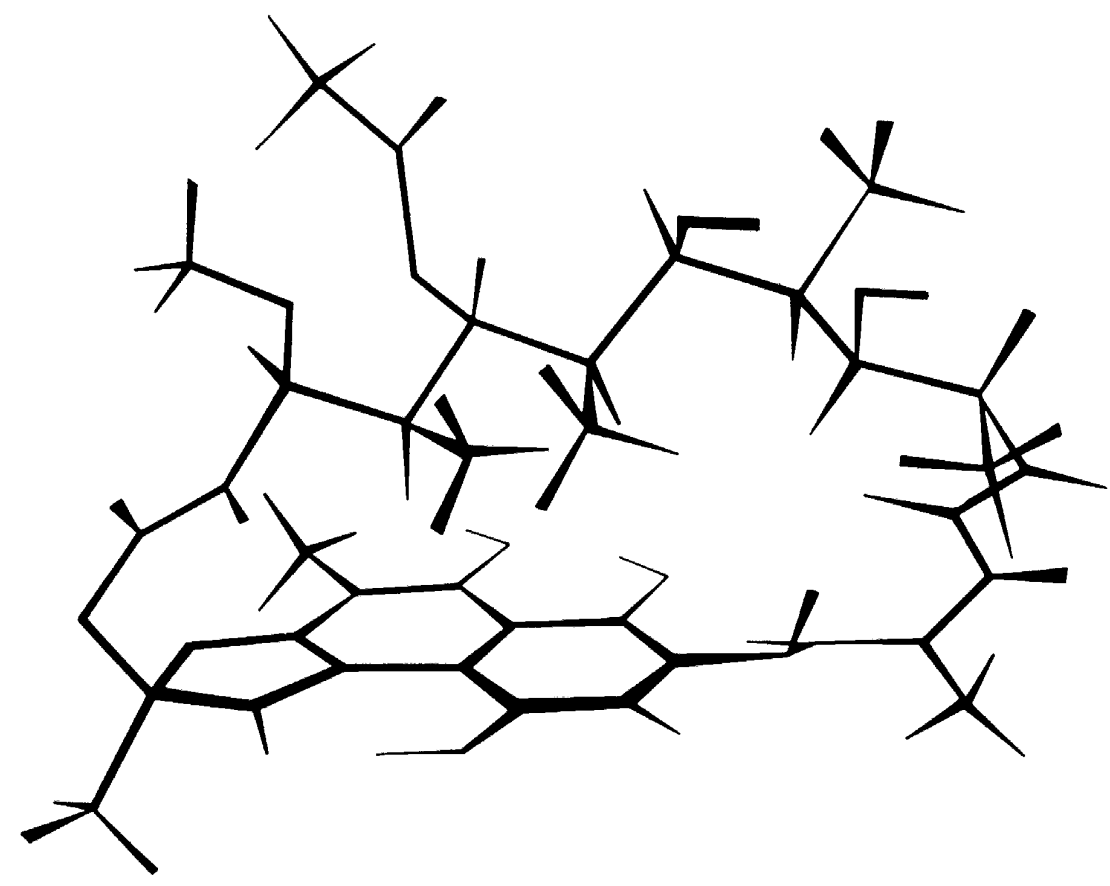

Figure 11. Conformational model of rifamycin SV.

Figures 12 and 13 indicate the principal classes of rifamycin derivatives with substitutions in position 3,4 , or both, studied in the course of several years : amides and hydrazides of rifamycin $\mathrm{B}^{61}$; quinonimino rifamycins ${ }^{62,63}$; 4-dialkylamino-4-deoxy-rifamycins ${ }^{64}$; phenazino- and phenoxazino-rifamycins ${ }^{59,65}$; pyrrolorifamycins ${ }^{66}$; 3-thioalkyl-67, 3-dialkylamino-59, 3dialkylaminoalkyl ${ }^{68}$, 3-formyl-rifamycin $\mathrm{SV}$ and its functional derivatives $^{69,70}$. The fact that substitutions in these positions with various substituents do not affect dramatically the antibacterial activity, indicates that this side of the molecule does not play an important role in the binding with the bacterial RNA polymerase.

Some differences have been observed in the in vitro antibacterial activity of the various classes of these derivatives, but they are most likely due to differences in the ability to penetrate into the bacterial cell, rather than to differences in the activity on RNA polymerase. As an example, Table 5 


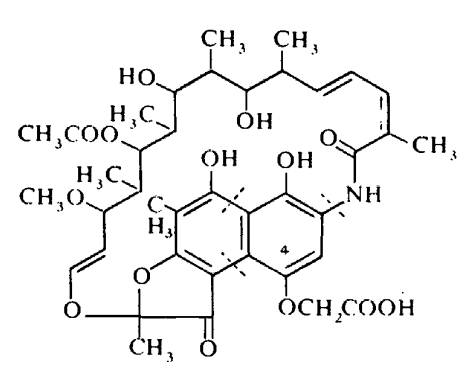

Rifamycin B

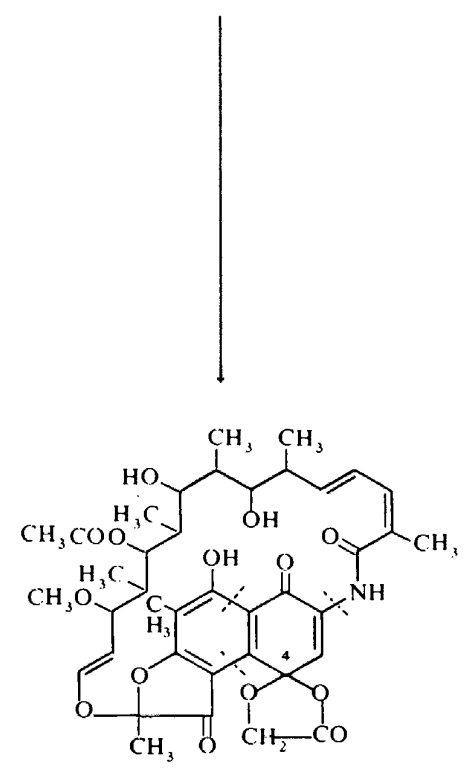

Rifamycin $\mathrm{O}$
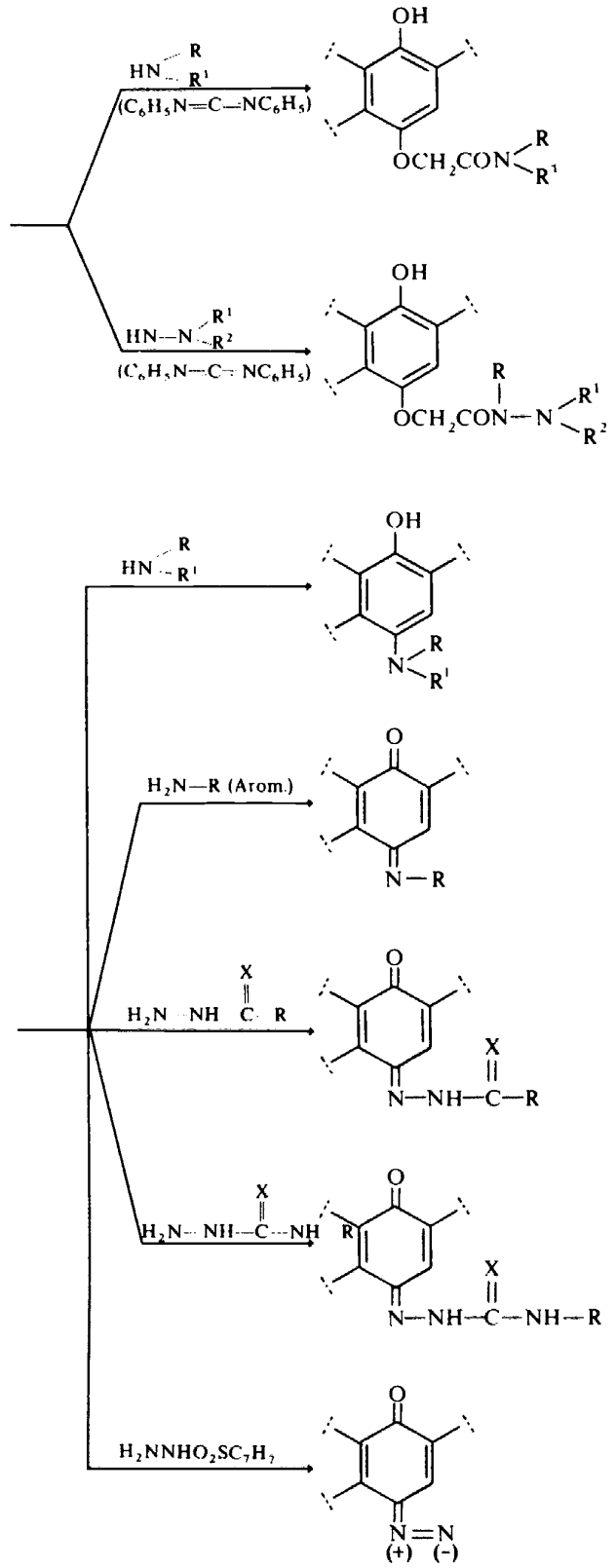

$\mathrm{H}_{2}$<smiles>Oc1c(I)ccc(I)c1I</smiles>

Figure 12. Rifamycins modified in position 4 of the aromatic moiety with high antibacterial activity $(+++$, according to Figure 10 .) 


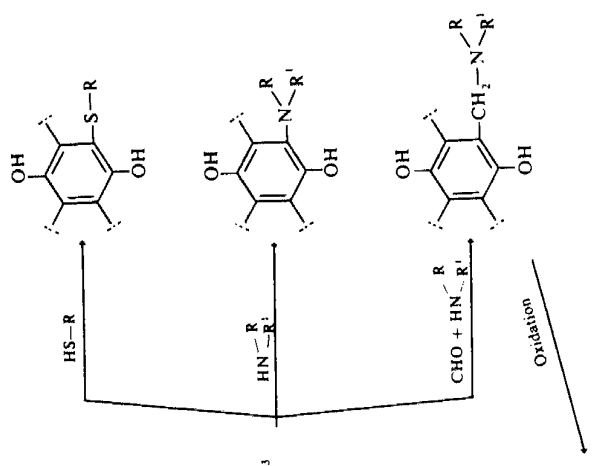

용
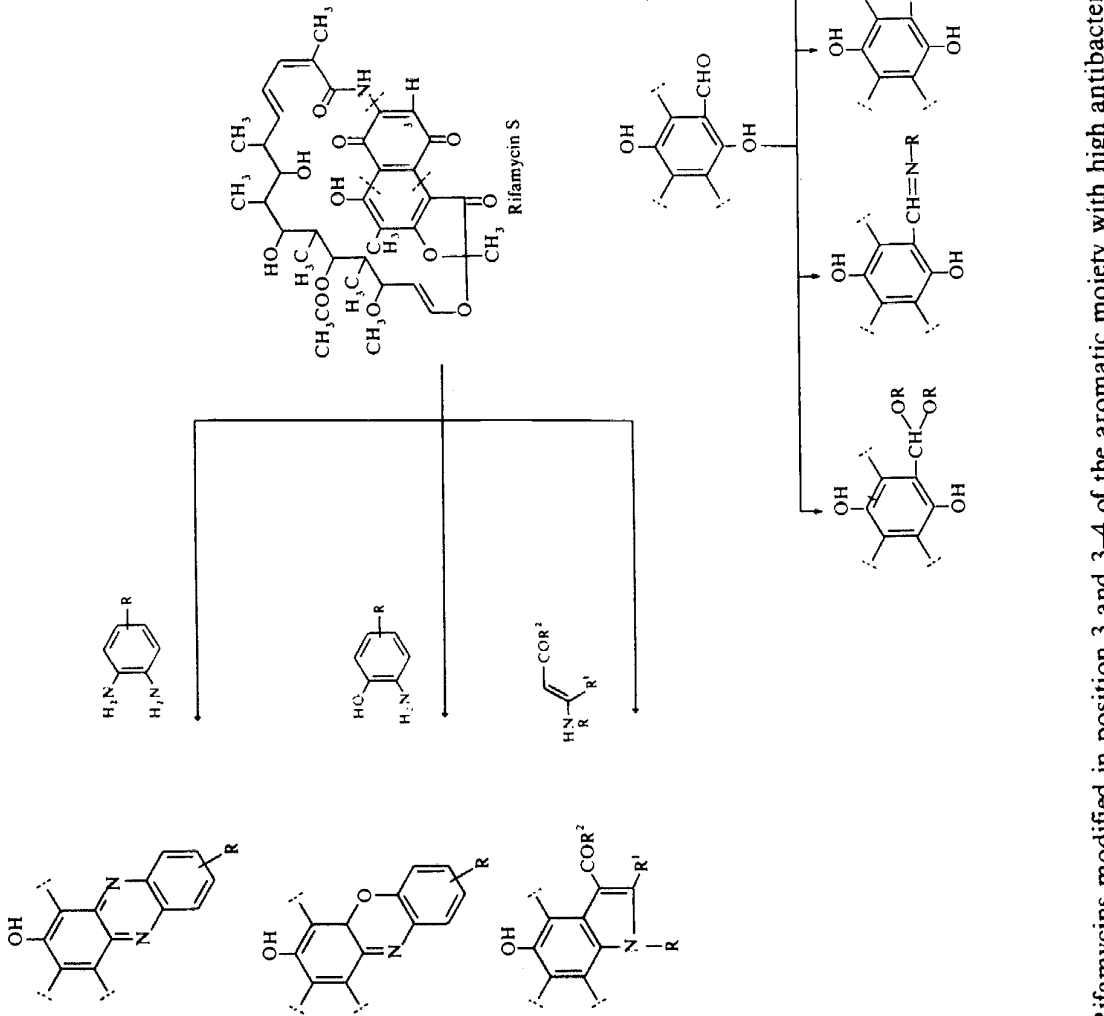


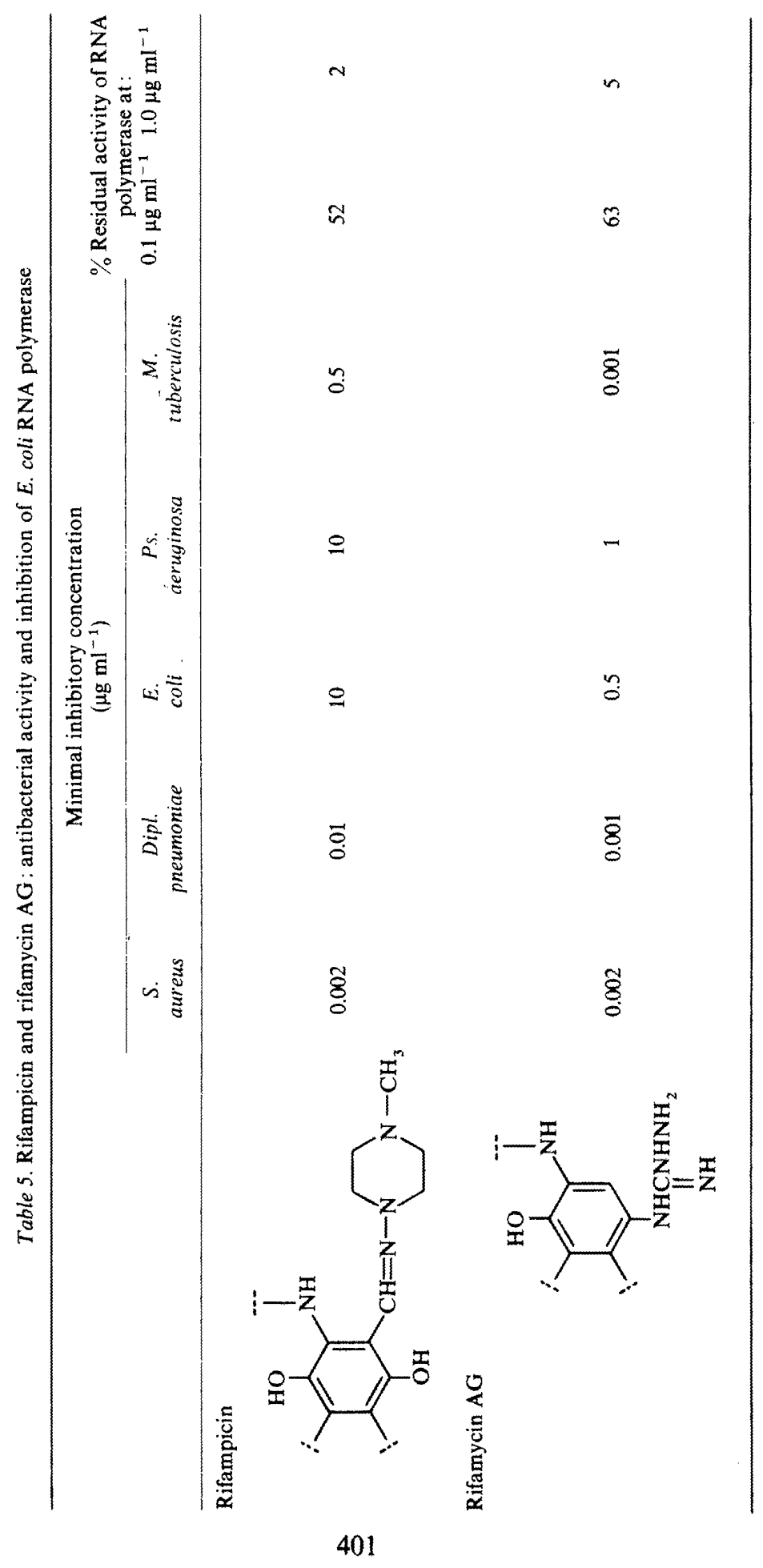




\section{P. SENSI}

reports the activity of rifampicin and rifamycin $A G$ against several bacteria and against RNA polymerase. Although rifamycin AG is about 20 times more active than rifampicin against $E$. coli, the RNA polymerase extracted from this bacterial species is equally sensitive to both substances ${ }^{60}$.

These chemical modifications on the aromatic moiety have produced dramatic changes on the pharmacokinetic behaviour of the resulting rifamycins in comparison with rifamycin SV, the first rifamycin used in therapy for the treatment of several infectious discases. This modified pharmacokinetic behaviour is, in turn, the result of changes in physicochemical parameters (such as solubility and partition coefficient in water and lipids).

Rifampicin ${ }^{69,71}$ has been selected out of several hundred derivatives for its high in vivo activity per os and is now successfully used for the oral treatment of Gram-positive and some Gram-negative infections and tuberculosis ${ }^{72}$.

The field of rifamycins is another example showing that the selectivity of action against bacteria is a necessary requisite for the development of a potential chemotherapeutic agent, but that its practical usefulness depends on several other factors (absorption, distribution, rate of elimination, metabolism, interaction with proteins, etc.).

\section{Modifications resulting in activity against rifampicin-resistant bacterial mutants}

A possible target for new chemically modified rifamycins is the RNA polymerase of resistant bacteria, with the aim of overcoming the possible decline in the therapeutic value of these antibiotics as a consequence of the

Table 6. Activity of some rifamycin derivatives against sensitive and resistant strains of S. aureus

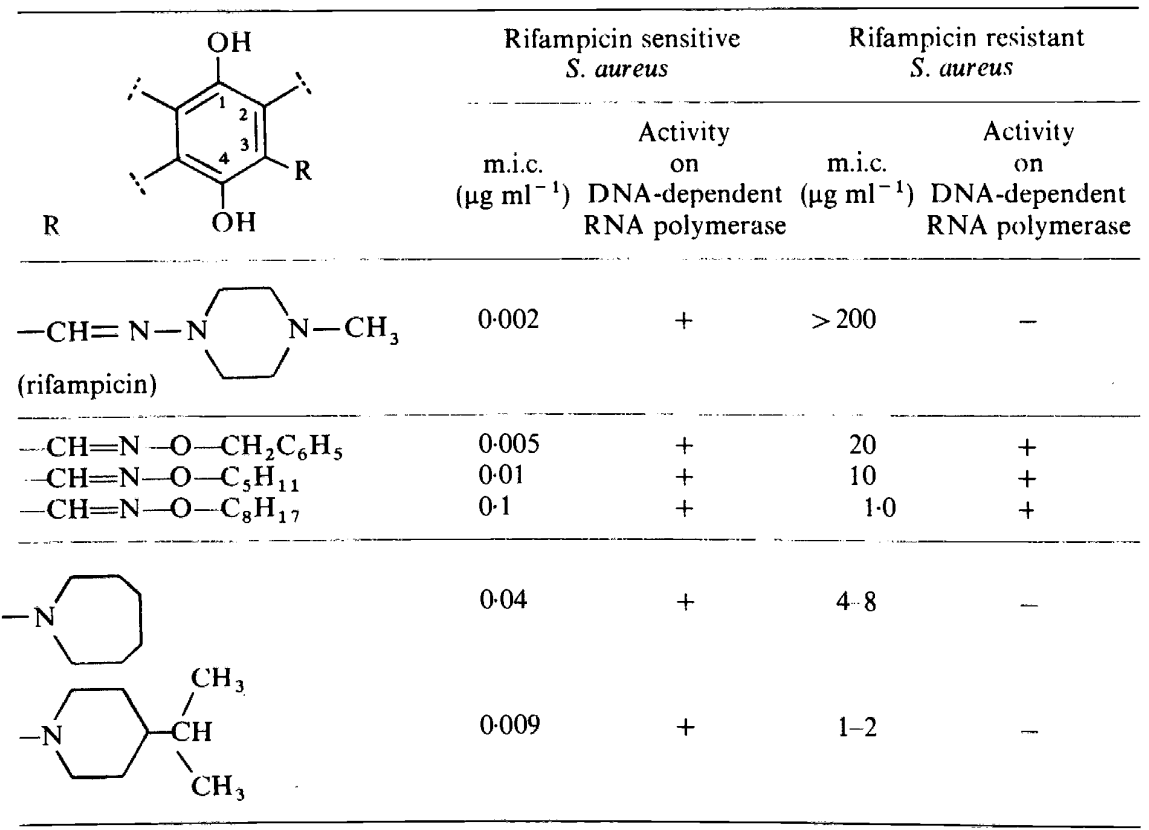


emergence of organisms insensitive to them. As mentioned, in the resistant mutants the subunit $\beta$ of the RNA polymerase is modified and is no more affected by rifampicin and by the other rifamycins in clinical use.

Testing hundreds of semisynthetic rifamycins, it has been found that some groups of derivatives inhibit, at concentration inferior to $20 \mu \mathrm{g} \mathrm{ml}^{-1}$, the growth of a Staphylococcus strain resistant to more than $200 \mu \mathrm{g} \mathrm{ml}^{-1}$ of rifampicin. In Table 6 two groups of derivatives are reported: the oximes of the 3 -formylrifamycin $\mathrm{SV}^{73}$, and the 3-N,N-disubstituted aminorifamycins ${ }^{74}$.

Although the oximes do have a certain activity on the isolated RNA polymerase from rifampicin-resistant bacteria, it cannot be concluded that this is the only responsible mechanism of inhibition of the intact bacteria. The oximes inhibit other enzymes as well (see reverse transcriptase p. 407) and have lost, at least partially, the specificity of the parent molecule.

The 3-N,N-disubstituted aminorifamycins active on $S$. aureus resistant to rifampicin had no effect on the RNA polymerase extracted from the resistant cells. In this case a different mechanism of action should be responsible for this activity on resistant mutants. The compounds reported in Table 6 have no practical interest, because their minimal inhibitory concentration is too high to foresee a therapeutic use for them, but the case of oximes is indicative that some structural modifications of the rifamycin molecule could permit the obtaining of inhibitors of the RNA polymerase resistant to rifampicin.

\section{ACTIVITY OF RIFAMYCINS ON VIRAL TRANSCRIPTASES}

\section{Transcriptase from mammalian cytoplasmic DNA viruses}

A DNA-dependent RNA polymerase is contained in the virions of some large mammalian cytoplasmic DNA viruses such as pox viruses ${ }^{75}$. Specific inhibitors of this enzyme might be potentially useful antiviral agents. Rifampicin was found to inhibit the growth of pox viruses, but its viral inhibitory dose $\left(100 \mu \mathrm{g} \mathrm{ml}^{-1}\right)$ is from 1000 to 10000 times higher than the antibacterial one $^{76,77}$. The mechanism of the antiviral activity of rifampicin has been the object of many studies with conflicting conclusions. Although the antibiotic shows some action on the transcription of the viral genome, the inhibition of vaccinia virus growth seems to be related to a block in the assembly of preformed structural polypeptides of the virion ${ }^{78-80}$. Other evidence that the mechanism of action of rifampicin against pox viruses is different from that against bacteria derives from the fact that virion-associated RNA polymerase of resistant mutants is sensitive to the same concentrations of rifampicin as the wild-type ${ }^{81}$. Furthermore, a number of different rifamycin derivatives active on the bacterial polymerase are not inhibitory of vaccinia plaque formation ${ }^{81,82}$. On the other hand, it has been reported that one rifamycin derivative; 23-dehydroxy-27-demethoxy-23,27 epoxyrifamycin SV (see Figure 10), which does not react with the bacterial polymerase, inhibits the vaccinia virus enzyme ${ }^{83}$. This fact indicates that some structural changes on the ansa chain could confer on the rifamycin molecule the property of blocking the viral enzyme. Assuming that the mechanism of action of rifampicin is different in bacteria and viruses, the discovery of its antiviral activity can be considered as a case of serendipity. 


\section{P. SENSI}

Until now neither rifampicin nor other semisynthetic rifamycins show significant therapeutic activity in experimental viral infections.

\section{Reverse transcriptase (RNA-dependent DNA polymerase) from oncogenic RNA viruses}

It is known that tumours can be induced in animals by various chemical, physical and biological triggers. Many DNA and RNA viruses are oncogenic in animals. They do not multiply in the cell causing its death, but determine a morphological transformation of the cell, whose subsequent multiplication is in part controlled by viral genes, integrated into the cell genome. In the case of DNA tumour viruses, replication of the viral genetic material and its expression is basically in symbiosis with the host metabolism. Also for the RNA oncogenic viruses, which constitute a large group of animal viruses, also called leukoviruses, the viral information is integrated into the cell genome and is transmitted to the daughter cells.

The structure containing the viral information was called provirus by Temin $^{84}$, who hypothesized in 1964 that replication of RNA tumour viruses had to involve a DNA intermediate using the viral RNA as template. This hypothesis was at that time in contrast with the established concept of information transfer, but was confirmed in 1970 when Temin and Mizutani ${ }^{85}$ and Baltimore ${ }^{86}$ independently demonstrated the presence of the RNA-dependent DNA polymerase in Rous sarcoma virus and in Rauscher leukaemia virus. The enzyme is called also 'reverse transcriptase' and its presence has been confirmed in at least 40 RNA oncogenic viruses. The non-oncogenic RNA viruses do not contain an RNA-dependent DNA polymerase activity.

The RNA tumour virus replication and cell transformation can be indicated schematically as shown below:

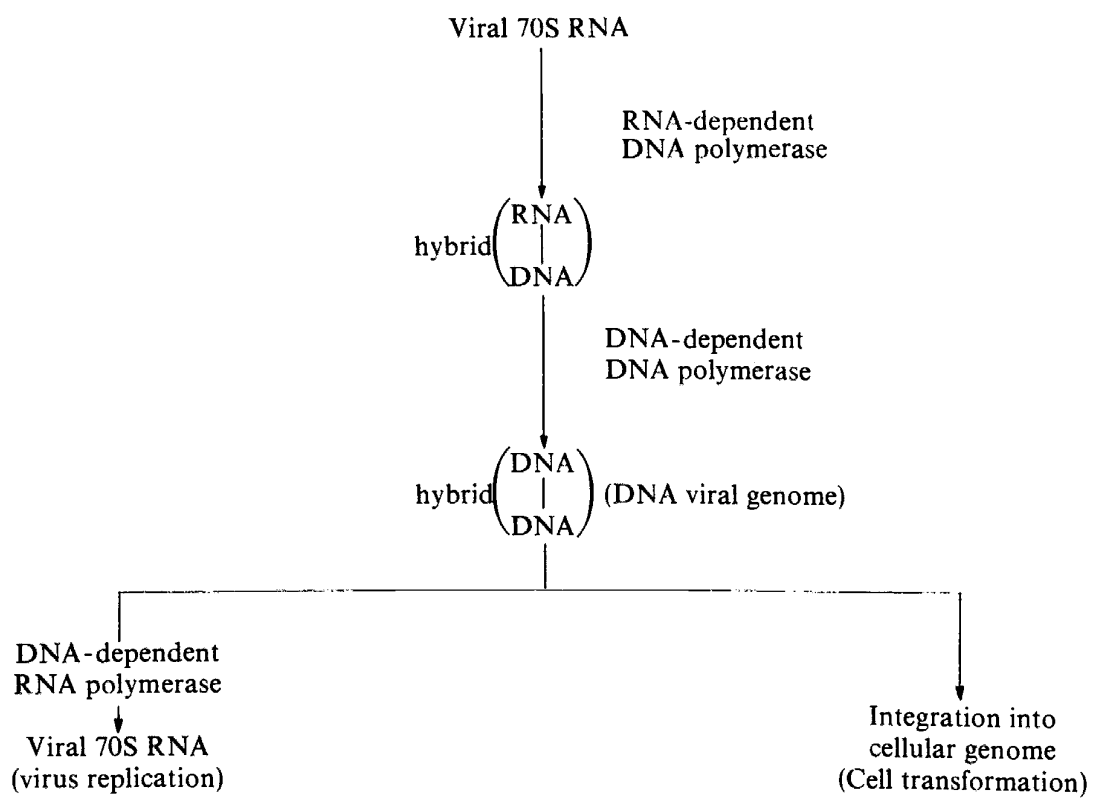


RNA-dependent DNA polymerase activity has been found in the milk of women from families with a history of breast cancer. Such milk was also found to contain particles morphologically identical to the type B mouse mammary tumour virus ${ }^{87}$. A similar enzymatic activity has been identified in leukocytes of some patients with acute leukaemia and not in lymphocytes of healthy subjects even when mitosis was induced with phytohaemagglutinin $^{88,89}$. The molecular weight of the enzymes from avian myeloblastosis virus and from Rous sarcoma virus have been reported to be about 110000 and that from Rauscher leukaemia virus about $70000^{90-92}$. The structure of the enzyme(s) is not known.

The RNA-dependent DNA polymerase activity is sensitive to ribonuclease and requires all four deoxyribonucleotides for the reaction. The activity is stimulated by the addition of exogenous, synthetic DNA-RNA hybrid templates.

The reverse transcriptase of RNA tumour viruses of human acute leukaemic cells can be distinguished from known normal cellular DNA-directed DNA polymerases on the basis of its response to certain oligomer-homopolymer complexes $^{93,94}$. In fact, reverse transcriptase responds very well to oligo(dT). poly(rA) templates and very poorly to oligo(dT).poly(dA) templates, while DNA polymerases of calf thymus or normal human lymphocytes and of bacteria have a different behaviour. The ratio of DNA polymerase activity using the two indicated oligopolymer-homopolymer complexes as templates is indicative of the reverse transcriptase activity.

Although the aetiology of human neoplasia is not known, a number of hypotheses implicate the reverse transcriptase at some stage in the process of cancerogenesis.

Inhibitors of the reverse transcriptase could constitute a powerful tool for understanding the role of reverse transcriptase in viral cancerogenesis, and perhaps could have an inhibitory effect on tumour induction or on tumour growth. Rifamycins and streptovaricins have been tested for their effect on reverse transcriptase.

Rifampicin was found to be inactive, but some derivatives with modified aminopiperazine side chains showed an inhibitory effect on reverse transcriptase of MSV (murine sarcoma virus) Fe LV (feline leukaemia virus) and AMV (avian myeloblastosis virus). The most active ones were initially indicated to be rifamycins AF/ABDP (2,6-dimethyl-4-benzyl-4-demethyl-rifampicin), AF/ABP (4-benzyl-4-demethyl-rifampicin) and AF/AP (4-demethyl-rifampicin) ${ }^{95,96}$. The three rifamycins inhibited the enzyme activity more than 50 per cent at 50 to $100 \mu \mathrm{g} \mathrm{m}^{-1}$. The most effective inhibitor, AF/ABDP, blocked 95 per cent to 100 per cent of the enzyme activity at $100 \mu \mathrm{g} \mathrm{ml}^{-1}$. 4-Demethylrifampicin caused complete inhibition only at a concentration $>200 \mu \mathrm{g} \mathrm{ml}^{-1}$.

The streptovaricin complex has been reported to cause a 75 per cent inhibition of the reverse transcriptase activity of MLV (Moloney leukaemia virus) at a concentration of $40 \mu \mathrm{g} \mathrm{ml}^{-197}$.

Other in vitro effects of ansamycins on the oncogenic RNA viruses have been observed. Rifampicin inhibits focus formation in chick embryo cells infected by Rous sarcoma virus ${ }^{98}$ and rifamycin AF/ABDP inhibits transformation of mouse cells by murine sarcoma virus ${ }^{99}$. 
P. SENSI

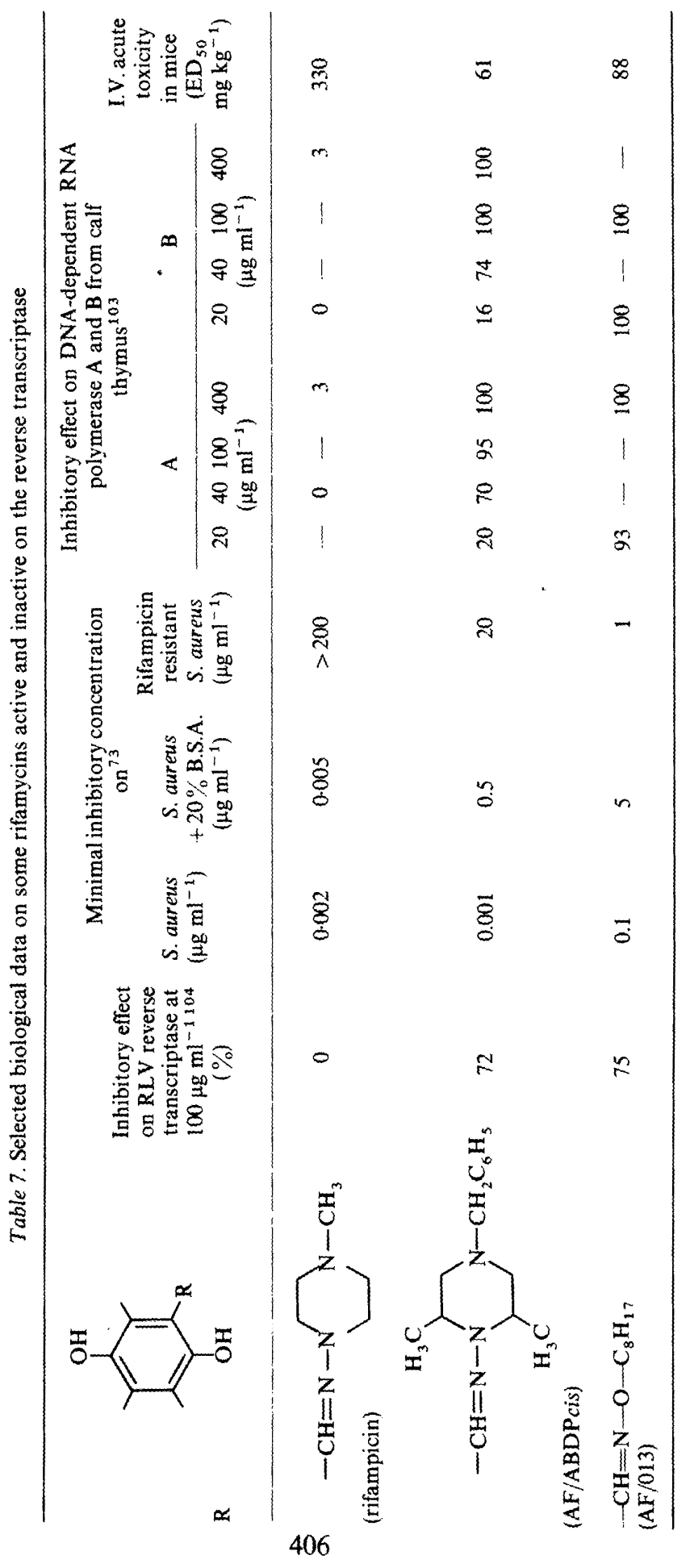


All these data stimulated a search for potent inhibitors of the reverse transcriptase and more than 200 rifamycin derivatives were tested for their effect on this enzyme ${ }^{100,101}$. Whereas the majority of semi-synthetic rifamycins are inactive, or moderately active, some derivatives are quite effective inhibitors, blocking the RNA-dependent DNA polymerase reaction at concentrations of less than $20 \mu \mathrm{g} \mathrm{ml}^{-1}$. Most of these compounds have bulky substituents in position 3, e.g. the hydrazones and oximes of 3 -formyl rifamycin SV. Also the 3-cyclic amino derivatives of rifamycin SV that contain cyclohexyl substituents, exhibit a high degree of activity on DNA polymerase of MSV ${ }^{102}$. This extensive screening has demonstrated the possibility of reaching a relatively high activity against reverse transcriptase through adequate modification of the rifamycin molecule. But a question immediately arises concerning the selectivity of action of these derivatives. In a screening of certain rifamycin derivatives for their effect on animal polymerases it was found that some of them completely inhibit the calf thymus DNA-dependent RNA polymerase AI and B activities at concentrations of 20 to $40 \mu \mathrm{g} \mathrm{ml}^{-1} 103$.

Among the most active are the same derivatives, such as rifamycin $\mathrm{AF}$ / $\mathrm{ABDP}$ and rifamycin AF/013 (octyloxime of 3-formyl rifamycin SV), selected for their high activity on reverse transcriptase. The lack of specificity of some of these derivatives is indicated by some selected biological data reported in Table $7^{103,104}$. The two derivatives AF/ABDP cis and AF/013, active on RLV reverse transcriptase, show a remarkable loss of activity against sensitive $S$. aureus strain in the presence of bovine serum albumin, good activity against a $S$. aureus strain resistant to rifampicin, high inhibitory effect on animal DNA-dependent RNA polymerases and a remarkably acute toxicity in mice. Therefore it seems that these derivatives cannot be used as specific inhibitors of RNA-dependent DNA polymerase.

On the contrary rifampicin, which is inactive on reverse transcriptase and selectively active on bacterial RNA polymerase, shows only a minor loss of antibacterial activity in the presence of bovine serum albumen, no activity against animal RNA polymerases and is less toxic than the other compounds.

All these data tend to indicate that for some rifamycin derivatives a higher activity against reverse transcriptase was achieved together with a broader spectrum of activity against other transcriptases and therefore with poor selectivity. This could not be the case for other derivatives and in fact Gallo et al. ${ }^{104}$ pointed out that $N$-demethylrifampicin and 3-2,4-dinitrophenylhydrazonomethyl) rifamycin SV inhibit leukaemic polymerases more strongly than the analogous normal enzymes (Table 8). Furthermore some rifamycin derivatives, active on reverse transcriptases of both human and viral origin, have been found to be more toxic for fresh human leukaemic blood cells than for normal proliferating blood cells ${ }^{105}$. Although the mechanism of the selective toxicity for the leukaemic blood cells is not clarified, and is not necessarily related to the inhibitory activity on reverse transcriptase, this effect could be chosen for the selection of potentially useful chemotherapeutic agents.

In summary, the screening of many semisynthetic rifamycins for their activity on reverse transcriptase revealed a series of potent, but not specific, inhibitors of this polymerase. Only a few derivatives seem to have a moderate specificity of action against this enzyme. On the other hand, viral and cellular polymerases have remarkable structural differences as indicated by their 


\section{P. SENSI}

Table 8. Relative differences between inhibition of purified DNA polymerase activities from leukaemic and normal (1788) lymphoblasts ${ }^{104}$

Rifamycin<smiles>[R]c1c(O)c(I)c(I)c(O)c1I</smiles>

Inhibitory concentration for $50 \%$ inhibition $\left.(\mu \mathrm{g} \mathrm{ml})^{-1}\right)$

(Poly d(AT) template)

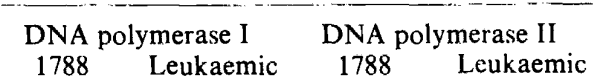

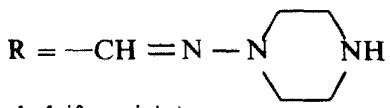

$>1000>1000 \quad>750$

100

( $N$-demethylrifampicin)

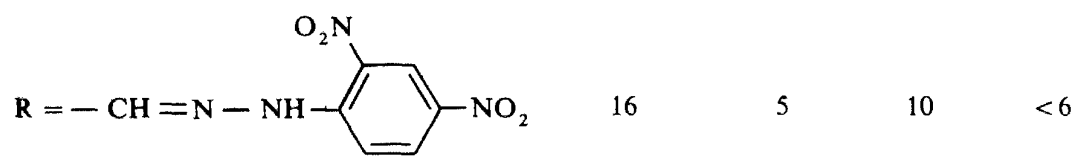

different template specificities and cellular functions ${ }^{102}$. Therefore, at least theoretically, it should be possible to develop specific inhibitors of the DNA polymerase of RNA tumour viruses.

A systematic study of semisynthetic or new natural ansamycins with new modifications both in the aromatic nucleus and on the ansa chain could perhaps lead to a knowledge of the structural requirements for the specific inhibitory effect on reverse transcriptase. A product with such a property will be a powerful tool for understanding the role of the reverse transcriptase in the process of tumour induction and propagation. Furthermore, if the enzyme plays a definite role in these processes, a specific inhibitor will have the necessary requisite of a potential chemotherapeutic agent.

\section{ACKNOWLEDGMENT}

I wish to thank Dr. R. White and Dr. E. Terenzi for their very helpful assistance in revising the manuscript.

\section{REFERENCES}

1 R. Ferone, J. J. Burchall and G. H. Hitchings, Mol. Pharmacol. 5, 49 (1969).

2 S. P. Biatti, C. J. Ingles, L. J. Lindell, P. W. Morris, R. F. Weaven, F. Weinberg and W. J. Rutter, Cold Spring Harbor Symp. Quant. Biol. 35, 649 (1970).

3 R. F. Weaven, S. P. Biatti and W. J. Rutter, Proc. Nat. Acad. Sci. US, 68, 2994 (1971).

${ }^{4}$ R. R. Burgess, A. A. Travers, J. J. Dunn and E. K. F. Bautz, Nature, 221, 43 (1969).

$s$ T. Wieland, Science, 159, 946 (1968).

6 L. Fiume and F. Stirpe, Biochim. Biophys. Acta, 123, 643 (1966).

7 T. J. Lindell, F. Weinberg, P. W. Morris, R. G. Roeder and W. J. Rutter, Science, 170, 447 (1970).

8 S. Dezelee, A. Sentenac and P. Fromageot, FEBS Lett. 7, 220 (1970). 


\section{INHIBITORS OF THE TRANSCRIBING ENZYMES}

9 L. K. Rinehart, J. R. Beck, D. B. Borders, T. H. Kinstle and D. Krauss, J. Am. Chem. Soc. 85, 4038 (1963).

10 M. Gniadowski, J. L. Mandel, F. Gissinger, C. Kedinger and P. Chambon, Biochem. Biophys. Res. Commun. 38, 1033 (1970).

11 G. Cassani, R. R. Burgess, A. M. Goodman and L. Gold, Nature New Biology, 230, 197 (1971).

12 P. Sensi, P. Margalith and M. T. Timbal, Farmaco (Pavia) Ed. Sci. 14, 146 (1959).

13 P. Sensi, A. M. Greco and R. Ballotta, Antibiotics Ann. 262 (1959).

${ }^{14}$ V. Prelog, in The chemistry and biochemistry of fungi and yeasts 551, Butterworths, London (1963).

15 W. Oppolzer, V. Prelog and P. Sensi, Experientia, 20, 3.36 (1964).

16 J. Leitich, W. Oppolzer and V. Prelog, Experientia, 20, 343 (1964).

17 M. Brufani. W. Fedeli, G. Giacomello and A. Vaciago. Experientia, 20, 339 (1964).

18 J. Leitich, V. Prelog and P. Sensi, Experientia, 23, 505 (1967).

19 M. Brufani, W. Fedeli, G. Giacomello and A. Vaciago, Experientic, 23, 508 (1967).

20 G. C. Lancini, G. G. Gallo, G. Sartori and P. Sensi, J. Antibiotics, 22, 369 (1969).

21 G. C. Lancini, C. Hengeller and P. Sensi, in Progress in Antimicrobial and Anticancer Chemotherapy Part II, 1166, Univ. Tokyo Press, Tokyo (1970).

22 S. Sugawara, K. Karasawa, M. Watanabe and T. Hidaka, J. Antibiotics, 17, 29 (1964).

23 I. Takagi, S. Iriyama and S. Umezawa, Proc. Fujihara Mem. Fac. Eng. Keio Univ. (Tokyo), 19, 163 (1966).

24 G. C. Lancini and C. Hengeller, J. Antibiotics, 22, 637 (1969).

${ }^{25}$ T. Kishi, M. Asai, M. Muroi, S. Harada, E. Mizuta, S. Teroo, T. Miki and K. Mizuno, Tetrahedron Letters, 91 (1969).

26 T. Kishi, S. Harada, M. Asai, M. Muroi and K. Mizuno, Tetrahedron Letters, 97 (1969).

${ }^{27}$ P. Siminoff, R. M. Smith, W. T. Sokolski and G. M. Savage, Am. Rev. Resp. Diseases, 75, 576 (1957).

${ }^{28}$ K. L. Rinehart, M. L. Maheshwari, K. Sasaki, A. J. Schacht, H. H. Mathur and F. J. Antosz, J. Am. Chem. Soc. 93, 6273 (1971).

29 K. L. Rinehart and J. F. Antosz, J. Antibiotics, 25, 71 (1972).

${ }^{30}$ C. Calvori, L. Frontali, L. Leoni and G. Tecce, Nature, 207, 417 (1965).

${ }^{31}$ H. Umezawa, S. Mizuno, H. Yamazaki and K. Nitta, J. Antibiotics, 21, 234 (1968).

32 G. Hartmann, K. O. Honikel, F. Knusel and J. Nuesch, Biochem. Biophys. Acta, 145, 843 (1967).

33 G. C. Lancini and G. Sartori, Experientia, 24, 1105 (1968).

34 G. C. Lancini, R. Pallanza and L. Silvestri, J. Bacteriol. 97, 761 (1969).

${ }^{35}$ E. Winterzberger and V. Winterzberger, FEBS Letters, 6, 58 (1970).

${ }^{36}$ S. Yang and R. S. Criddle, Biochemistry,9, 3063 (1970).

37 F. Herzfeld, Z. Physiol. Chem. 351, 658 (1970).

38 D. T. Dubin and B. S. Montenecourt, J. Mol. Biol. 48, 279 (1970).

39 M. N. Gadaleta, M. Greco and C. Saccone, FEBS Letters, 10, 54 (1970).

40 J. G. Gamble and R. H. Mc. Cluer, J. Mol. Biol. 54, 557 (1970).

41 Z. G. Schmerling, Biochem. Biophys. Res. Commun. 37, 965 (1969).

42 A. Sippel and G. Hartmann, Biochem. Biophys. Acta, 157, 218 (1968).

${ }^{43}$ H. Lill, U. Lill, A. Sippel and G. Hartmann, in RNA Polymerase and transcription 55. Proc. 1st Lepetit Colloq. North-Holland Publishing Co., Amsterdam (1970).

44 A. Sippel and G. Hartmann, Eur. J. Biochemistry, 16, 152 (1970).

45 V. Neuhoff, W. B. Schill and H. Sternbach, Z. Physiol. Chem. 350, 335 (1969).

46 W. Wehrli, K. Knüsel, K. Schmid and M. Staehelin, Proc. Nat. Acad. Sci.US, 61, 667 (1968).

47 W. Wehrli and M. Staehelin, Biochim. Biophys. Acta, 182, 24 (1969).

$48 \mathrm{~W}$. Wehrli and M. Staehelin, in RNA Polymerase and transcription 65, Proc. 1st Int. Lepetit Colloq. North-Holland Publishing Co., Amsterdam (1970).

49 W. Wehrli, F. Knusel and M. Staehelin, Biochem. Biophys. Res. Commun. 32, 284 (1968).

so G. P. Tocchini-Valentini, P. Marino and A. J. Calvill, Nature, 220, 275 (1968).

51 A. Heil and W. Zillig, FEBS Letters, 11, 165 (1970).

52 W.Zillig. E. Fuchs, P. Palm, D. Rabussay and K. Zechel, in RNA Polymerase and transcription 151. Proc. 1st Int. Lepetit Colloq. North-Holland Publishing Co., Amsterdam (1970).

53 D. Rabussay and W. Zillig, FEBS Letters, 5, 104 (1969).

54 N. Maggi, S. Furesz and P. Sensi, J. Med. Chemistry, 11, 368 (1968).

55 P. Sensi, R. Ballotta, A. M. Greco and G. G. Gallo, Farmaco (Pavia) Ed. Sci. 16, 165 (1961).

56 P. Sensi, N. Maggi, S. Furesz and Maffii. Antimicrohial Agents and Chemotherapy, 699 (1966).

57 N. Maggi, A. Vigevani, G. G. Gallo and C. R. Pasqualucci, J. Med. Chem. 11, 936 (1968). 


\section{P. SENSI}

58 N. Maggi, A. Vigevani and R. Pallanza, Experientia, 24, 209 (1968).

${ }^{59}$ H. Bickel, F. Knusel, W. Kump and L. Neipp, Antimicrobial Agents and Chemotherapy, 352 (1966).

60 R. J. White-Personal communication.

61 P. Sensi, N. Maggi, R. Ballotta, S. Furesz, R. Pallanza and V. Arioli, J. Med. Chem. 7, 596 (1964).

62 A. M. Greco, R. Ballotta and P. Sensi, Farmaco (Paida) Ed. Sci. 16, 755 (1961).

63 P. Sensi, M. T. Timbal and A. M. Greco, Antibiot. Chemotherapy, 12, 488 (1962).

64 R. Cricchio and G. Tamborini, J. Med. Chem. 14, 721 (1971).

65 G. G. Gallo, C. R. Pasqualucci, N. Maggi, R. Ballotta and P. Sensi, Farmaco (Pavia) Ed. Sci. 21, 68 (1966).

${ }^{66}$ N. Maggi, V. Arioli and G. Tamborini, Farmaco (Pavia) Ed. Sci. 24, 263 (1969).

67 N. Maggi and R. Pallanza, Farmaco (Pavia) Ed. Pr. 22, 307 (1967).

${ }_{68}$ N. Maggi, V. Arioli and P. Sensi, J. Med. Chem. 8, 790 (1965).

69 N. Maggi, R. Pallanza and P. Sensi, Antimicrobial Agents and Chemotherapy, 765 (1965).

70 S. Furesz, V. Arioli and R. Pallanza, Antimicrobial Agents and Chemotherapy, 770 (1965).

71 N. Maggi, C. R. Pasqualucci, R. Ballotta and P. Sensi, Chemotherapy, 11, 285 (1966).

72 G. Binda, E. Domenichini, A. Gottardi, B. Orlandi, E. Ortelli, B. Pacini and G. Fowst, Arzneim. Forsch. (Drug Res.), 21, 1907 (1971).

73 Unpublished results.

74 F. Knusel, H. Bickel and W. Kump, Experientia, 25, 1207 (1969).

75 J. R. Kates and B. R. McAuslan, Proc. Nat. Acad. Sci. US, 58, 134 (1967).

${ }^{76}$ E. Heller, M. Argamon, H. Levy and N. Goldblum, Nature, 222, 273 (1969).

77 J. H. Subak-Sharpe, M. C. Timbury and J. F. Williams, Nature, 222, 341 (1969).

78 T. H. Pennington, E. A. Follett and J. F. Szilagyi, J. Gen. Virol. 9, 225 (1970).

79 B. Moss, E. N. Rosenblum and P. M. Grimley, Virology, 45, 123 (1971).

80 B. Moss, E. N. Rosenblum and P. M. Grimley,Virology, 45, 135 (1971).

81 J. H. Subak-Sharpe, T. H. Pennington, J. F. Szilagyi, M. C. Timbury and J. F. Williams, in RNA Polymerase and Transcription 260, Proc. 1st Lepetit Colloq. North-Holland Publishing Co., Amsterdam (1970).

82 Z. Zakay and Y. Becker, Nature, 226, $1162(1970)$.

83 J. F. Szilagyi and T. H. Pennington, J. Virol. 8, 133 (1971).

84 H. M. Temin, Virology, 23, 486 (1964).

85 H. M. Temin and S. Mizutani, Nature, 226, 1211 (1970).

86 D. Baltimore. Nature, 226, 1209 (1970).

87 J. Schlom, S. Spiegelman and D. Moore, Nature, 231, 97 (1971).

88 R. C. Gallo, S. S. Yang and R. C. Ting, Nature, 228, 927 (1970).

89 R. C. Gallo, S. S. Yang, R. G. Smith, F. Herrera, R. C. Ting, S. N. Bobrow, C. Davis and S. Fujoka, in The Biology of Oncogenic Viruses 210, Proc. 2nd Lepetit Collq. North-Holland Publ. Co., Amsterdam (1971).

90 D. L. Kacian, R. F. Watson, A. Burny and S. Spiegelman, Biochim. Biophys. Acta, 246, 365 (1971).

91 P. Duesberg, K. V. D. Helm and E. Canaani, Proc. Nat. Acad. Sci. US, 68, 2505 (1971).

92 D. Baltimore and D. Smiler, Proc. Nat. Acad. Sci.US, 68, 1507 (1971).

93 N. C. Goodman and S. Spiegelman, Proc. Nat. Acad. Sci. US, 68, 2203 (1971).

94 M. S. Robert, R. G. Smith and R. C. Gallo, Science, 176, 798 (1972).

95 M. Green, M. Rokutanda, K. Fujinaga, H. Rokutanda, C. Gurgo, R. K. Ray and J. T. Parsons, in The Biology of Oncogenic Viruses, 193. Proc. 2nd. Lepetit Colloq. North-Holland Publ. Co., Amsterdam (1971).

96 C. Gurgo, R. K. Ray, L. Thiry and M. Green, Nature, 229, 111 (1971).

97 W. W. Brockman, W. A. Carter, L. Li, F. Reusser and L. R. Nichol, Nature, 230, 249 (1971).

98 H. Diggelman and C. Weissman, Nature, 224, 1277 (1969).

99 M. Calvin, U. R. Joss, A. J. Hackett and R. B. Owens, Proc. Nat. Acad. Sci.US, 68, 1441 (1971).

100 R. S. Yang, F. Herrera, R. G. Smith, M. Reitz, G. C. Lancini, R. C. Ting and R. C. Gallo, J. Nat. Cancer Inst. (in press).

101 C. Gurgo, R. Ray and M. Green, J. Nat. Cancer Inst. (in press).

102 M. Green, Proc. Nat. Acad. Sci.US, 69, 1036 (1972).

103 M. Meilhac, Z. Tysper and P. Chambon, Eur. J. Biochem. 28, 291 (1972).

104 R. C. Ting, S. S. Yang and R. C. Gallo, Nature New Biology, 236, 163 (1972).

105 R. G. Smith, J. Whang-Peng, R. C. Gallo, P. Levine, T. C. Ting, Nature New Biology, 236, 166 (1972). 